\title{
Arte, biología y tecnología. Relaciones interdisciplinares en el laboratorio científico
}

\author{
Art, biology and technology. Interdisciplinary relations \\ in the science lab
}

\author{
DANIEL LÓPEZ-DEL-RINCÓN \\ Universidad de Barcelona \\ dlopezdelrincon@gmail.com
}

Recibido: 8 de febrero de 2015

Aprobado: 12 de mayo de 2015

\section{Resumen}

El bioarte, entendido como la convergencia de las relaciones entre arte, biología y tecnología, constituye un caso de estudio emblemático para debatir el sentido de la interdisciplinariedad en el ámbito artístico. El artículo analiza distintas teorizaciones realizadas en torno a la interdisciplinariedad, cuestionando determinados planteamientos genéricos, por su ineficacia a la hora de valorar las prácticas artísticas. Se propone que el análisis de la interdisciplinariedad debe atender a la particularidad de las relaciones que se establecen en la misma práctica artística, planteando la imposibilidad de reducir la riqueza de los diálogos interdisciplinares a consideraciones genéricas. Tomando el bioarte como estudio de caso, se identifican y analizan distintas modalidades de relación entre el artista y el laboratorio científico, que abarcan desde la utilización del laboratorio como un verdadero atelier, hasta el rechazo del mismo mediante la propuesta de estrategias amateur, pasando por su utilización como fuente de técnicas y materiales.

Palabras clave: bioarte, interdisciplinariedad, laboratorio, sci-art.

López-del-Rincón, D. (2016): Arte, biología y tecnología. Relaciones interdisciplinares en el laboratorio científico. Arte, Individuo y Sociedad, 28(2) 235-252

\begin{abstract}
Bio art, understood as the convergence of the relations between art, biology and technology, constitutes a useful case study to discuss the meaning of interdisciplinarity in the artistic field. This paper explores different discourses around interdisciplinarity in order to challenge certain generic approaches for their ineffectiveness when assessing artistic practices. It is proposed that the analysis of interdisciplinarity must address the singular connections produced in the artistic practice itself, considering the impossibility of reducing the complexity of interdisciplinary dialogues into generic considerations. Taking bioart as a case study, different kinds of relationships between the artist and the lab are identified and analyzed, ranging from the use of the lab as a true atelier and as a resource for materials and techniques, to the rejection of the lab by proposing amateurism as an alternative. Keywords: bioart, interdisciplinarity, lab, sci-art.
\end{abstract}


Sumario: 1. El "bioarte" o el contexto de relaciones entre arte, biología y tecnología, 2. La interdisciplinariedad como marco teórico de relación entre arte y ciencia, 3. El artista en el laboratorio: modalidades y disidencias, 3.1. El laboratorio como atelier, 3.2. El laboratorio como fuente de materiales y técnicas, 3.3. El amateruismo como rechazo del laboratorio, 5. Conclusiones. Referencias.

Este artículo recoge, parcialmente, los resultados del proyecto "Arte y Sociedad Digital: Innovaciones Tecnológicas e Impacto Social (HAR2011-30347-C01) financiado por el Ministerio de Ciencia e Innovación.

\section{Introducción: El "bioarte" o el contexto de relaciones entre arte, biología y tecnología}

El término "bioarte" es un neologismo aparecido a principios del siglo XXI para designar genéricamente un conjunto de prácticas artísticas que relacionan arte, biología y, muy frecuentemente, tecnología. Esto ha hecho del "bioarte" un término que acoge un conjunto muy heterogéneo de prácticas cuyos límites no son siempre claros: se trata, en palabras de Natalie Jeremijenko, de un "umbrella term" (Jeremijenko y Thacker, 2005).

El significado atribuido al término "bioarte" ha variado en función de los distintos autores que lo han utilizado, lo que hace que una de sus características sea la flexibilidad: en algunos casos se utiliza una acepción muy amplia, que abarca toda utilización artística de materiales vivos; en otros casos, el bioarte se ha convertido en un término equivalente al de "arte biotecnológico", designando el conjunto de prácticas artísticas que se nutren de las investigaciones e innovaciones biotecnológicas, como la ingeniería genética, la ingeniería tisular o el cultivo celular y de microorganismos. Jens Hauser se ha referido a esta problemática del término "bioarte" describiéndolo como un "etymological monster" y como un "mutant term" (Hauser, 2005, p. 85).

A la cuestión de la indefinición y la pluralidad de usos del término "bioarte" se superpone el de la existencia de otras denominaciones tales como "arte biotecnológico", "arte genético" o "arte transgénico", que a menudo se han utilizado como sinónimos de "bioarte", lo que no resulta preciso atendiendo a su significado estricto. Sirva de ejemplo, con los términos mencionados, que todo arte transgénico es necesariamente genético pero no a la inversa y que, análogamente, toda intervención genética forma parte de la biotecnología, pero no a la inversa.

Tras la aparente homogeneidad del término "bioarte" se oculta un complejo y rico entramado de relaciones entre arte, biología y tecnología que, en la actualidad, abarca múltiples ámbitos: aplicaciones artísticas de la genética, como las técnicas del $\mathrm{ADN}$ recombinante, la mutación genética, la secuenciación genética o el aislamiento celular (con artistas como Joe Davis, Natalie Jeremijenko, Eduardo Kac o el colectivo Critical Art Ensemble); técnicas de cultivo celular y de microorganismos (con artistas como David Kremmers, Allison Kudla, Edgar Lissel o los colectivos Art Orienté Objet y Tissue Culture \& Art); y aplicaciones de la biología del desarrollo, la cría y selección de animales y el cultivo y selección de plantas (Marta de Menezes, Brandon Ballengée, George Gessert o Edward Steichen). 
La dificultad de definir los límites del término "bioarte" no ha impedido la articulación de un verdadero contexto de relaciones entre arte, biología y tecnología. Este ámbito artístico está recibiendo, especialmente desde el cambio de siglo, una notable atención por parte de artistas (de los que anteriormente hemos mencionado una muestra), de teóricos e instituciones de diverso tipo. Sin embargo, el interés artístico por las técnicas e investigaciones procedentes de la biología deben remontarse, al menos, a la década de los años veinte del siglo XX, con la aportación pionera de Edward Steichen. En paralelo a su trabajo como fotógrafo, Steichen desarrolló una investigación sobre las aplicaciones de la genética mendeliana, que le llevó a la producción de plantas, especialmente delphiniums, que llegaron a exponerse en el MoMA de Nueva York, bajo el título de Edward Steichen's Delphiniums (del 24 de junio al 1 de julio de 1936). Desde entonces el interés por parte de artistas y teóricos hacia las investigaciones e innovaciones biotecnológicas ha sido creciente hasta el punto de que pueden establecerse cuatro fases en su desarrollo: 1. Los precursores (1920-1985); 2. La primera generación de bioartistas (1980-1992); 3. De la hegemonía del arte genético a la heterogeneidad del arte biotecnológico (1993-2001); 4. La consolidación del bioarte como movimiento artístico (desde 2002) (López del Rincón y Cirlot, 2013).

Como manifestación que se encuentra a caballo del arte y la ciencia, el bioarte se inserta de lleno en el debate de la interdisciplinariedad que, en términos genéricos, concierne a la relación entre ciencias y humanidades y, en el caso específico que nos ocupa, a la posibilidad de establecer diálogos entre ellas por medio de las prácticas artísticas. Desde nuestro punto de vista, la interdisciplinariedad cobra sentido en el seno de la misma práctica y no como un conjunto de reflexiones genéricas que puedan aplicarse a los distintos casos, tal y como se debate a continuación.

\section{La interdisciplinariedad como marco teórico de relación entre arte y ciencia}

La interdisciplinariedad entendida como el espacio de diálogo entre arte, ciencia y tecnología ha sido teorizada de muy diversos modos aunque probablemente el más célebre sea el de la formulación de la "Tercera Cultura", que se situaría entre ciencias y humanidades. Fue Charles Pierce Snow el que a finales de la década de los cincuenta del siglo XX planteó la separación existente entre las dos culturas del saber: la científico-técnica y la artístico-humanística. En su libro The two cultures and the Scientific Revolution (Snow, 1959), el autor sostenía que humanidades y ciencias habían configurado unos ámbitos de conocimiento cuya especialización en los objetivos, en la metodología y en el mismo lenguaje impedía una concepción conjunta. El mismo autor publicó, posteriormente, una revisión del citado libro (Snow, 1963) donde abogaba por la necesidad de superar la distancia entre ambas culturas, anticipando el notable interés que en la actualidad tienen los estudios que se centran en la intersección entre arte, ciencia y tecnología. Más recientemente, en "Towards a Third Culture. Being in Between", Victoria Vesna ha señalado la importancia de situarse en ese lugar intermedio entre ciencias y humanidades como plataforma de conocimiento, que se identifica con la "Tercera Cultura": 
Thus we are placed in between these Two Cultures, which creates a triangle between art, science and the humanities that points to a potential emergence of a Third Culture. Being "in between" is a privileged and dangerous position, at least in this transitional stage. (Vesna, 2000, p. 7).

Esta manera de teorizar la relación existente entre humanidades y ciencia (que es extrapolable a la de arte y ciencia), pone de manifiesto el frecuente problema de la generalización de los términos ("humanidades", "arte", "ciencia, "técnica"), que designan elementos muy heterogéneos. Determinadas comparaciones entre arte y ciencia pueden llegar a ser sumamente estériles, bien por su carácter genérico, alejado de los matices de la práctica, como sería, a nuestro juicio, el planteamiento de Snow, o bien por su carácter estereotipado, como sería el caso de sendos artículos publicados por Jacques Mandelbrojt (Mandelbrojt, 2006) y Roger Guillemin (Guillemin, 2010) en la revista Leonardo, que reproducen un lugar común que contrapone la objetividad de la ciencia a la subjetividad del arte.

En el primer caso, Mandelbrojt toma una definición muy precisa y no universalmente válida, desde nuestro punto de vista, de lo que es arte: por un lado, se refiere fundamentalmente a artistas que utilizan medios tradicionales como la pintura y, por el otro, reduce la creación artística al terreno de la subjetividad y lo expresivo:

The domains of art and science are complementary: In the description of objective reality, science truly goes to the heart of matter with quantum mechanics and relativity. The domain of art is by contrast subjective reality as it exists in sensations, memory and imagination. (Mandelbrojt, 2006, p. 423).

Ello se traduce en el establecimiento de una clasificación excluyente de los ámbitos del arte y la ciencia: difieren, desde su punto de vista, no solo en los medios sino también en el carácter (subjetivo y objetivo) de sus actividades. Esta visión dicotómica resulta poco útil para entender manifestaciones como el bioarte, distorsionando determinadas orientaciones críticas del arte con respecto a la biotecnología, al relegarlo al lugar de lo especulativo o lo individual.

En el segundo caso, Roger Guillemin reproduce esta visión estereotipada del arte y la ciencia, asociando el primero al ámbito de lo anárquico y lo singular y a la segunda al del orden y la universalidad:

In scientific thinking, from one experimental step to another, as we have said, there are rules, what one can could even call laws, that there is no question of ignoring. (...) To continue, there can be no creativity in science without laws, whether they are already established ones, or ones to be established. This also force us to recognize that scientific knowledge must be universal and cannot be subject to individual, parochial or political interpretations. (...) Now I have said above that scientific creativity proceeds from the inside by ineluctable rules, but the artistic creativity that I know knows neither rules, still less laws. (Guillemin, 2010, p. 62).

Lo que tienen en común los planteamientos de Snow, Mandelbrojt y Guillemin es su carácter genérico, necesariamente reductivo, y que en el caso de los dos últimos es, además, parcial y estereotipado. Ello no implica que el razonamiento 
sea incorrecto pero sí que resulta poco ajustado a la realidad, en la medida en que la interdisciplinariedad está planteada en unos términos que resultan ineficaces a la hora de explicar prácticas concretas. El planteamiento de Snow es, sin duda, interesante desde un punto de vista teórico para conceptualizar la idea de la interdisciplinariedad. Sin embargo, parte de un dualismo que no recoge la heterogeneidad de elementos que encontramos en una y otra culturas del saber, anulando en parte la efectividad de sus planteamientos. Consecuentemente, la tercera cultura (entendida como híbrido que parte de ese dualismo entre ciencias y humanidades) debería subdividirse en tantas vías como posibilidades de interrelación existieran entre los múltiples elementos que conforman ambas culturas del saber.

En el texto "Comments on the relation of art and science" (Kuhn, 1969), el historiador de la ciencia Thomas S. Kuhn ya manifestó sus dudas con respecto a dicha visión estereotipada que caracteriza a las comparaciones entre arte y ciencia, rechazando las oposiciones entre lo objetivo y lo subjetivo, o lo intuitivo y lo inductivo, que se utilizan para distinguir a una y otra disciplina. La propuesta de Kuhn trata de ir, en este sentido, un paso más allá. Aunque sostiene que arte y ciencia son tareas intrínsecamente distintas cree que lo importante es establecer los términos en los que debe plantearse la comparación. Para Kuhn, los elementos que deben compararse son tres: los productos del científico y el artista; las actividades que han llevado a la realización de dicho producto y, finalmente, la recepción de estos productos por parte del público. Para nuestra investigación es especialmente relevante el análisis que el historiador de la ciencia realiza sobre los productos y actividades ya que, desde su punto de vista, estos elementos desempeñan una función opuesta en arte y ciencia (como medio o como fin), tal y como se explica a continuación.

Para el arte, la actividad es un medio para la obtención de un producto, que es el verdadero fin de la práctica artística: Kuhn pone el ejemplo de la pintura, aduciendo que, aunque el artista tenga que resolver diferentes problemas en la realización de la obra, su objetivo es la obtención del producto final. En cambio, para la ciencia, productos como las visualizaciones científicas (gráficos, fotografías microscópicas) son medios, en la medida en que no tienen valor en sí mismos sino como instrumento subsidiario a la actividad realizada, que sería el fin. En palabras de Kuhn:

Whatever the term "aesthetic" may mean, the artist's goal is the production of aesthetic objects; technical puzles are what he must resolve in order to produce such objects. For the scientist, on the other hand, the solved technical puzzle is the goal, and the aesthetic tool for its attainment. Whether in the realm of products or of activities, what are ends for the artist are means for the scientist, and vice versa. (Kuhn,1969, p. 343).

El valor del planteamiento de Thomas S. Kuhn es que la comparación entre arte y ciencia debe situarse en unos términos en los que ambas disciplinas puedan ser equiparadas (actividades, productos, recepción) para después analizar el papel que desempeñan en cada lugar. Aunque las conclusiones a las que llega Kuhn puedan ser matizables, en la medida en que sus ejemplos artísticos se reducen a pinturas, los términos en los que plantea la comparación entre arte y ciencia son muy acertados y contribuyen a comprender la cercanía que, en el bioarte, se produce entre ambas disciplinas, tanto como su cualitativa diferencia. 
Por su parte, Peter Weibel, en su texto "The Unreasonable Effectiveness of the Methodological Convergence of Art and Science" (Weibel, 1998), ha considerado que la teorización de las relaciones entre arte y ciencia debe explicitar los términos que intervienen en la comparación, es decir, a qué nos referimos con "ciencia" (a ciencias sociales, a ciencias humanas o a ciencias naturales, por ejemplo) o con "arte" (a artes visuales, artes sonoras o artes espaciales). Weibel alude, para ilustrar esta variedad de prácticas, a la cuestión histórica del paragone entre las artes, que alberga en su seno una disputa interna de cuál es, dentro del conjunto de artes, la más valiosa, mostrando colateralmente la diversidad de prácticas artísticas. La cuestión del paragone no es para Weibel ajena a las ciencias, y aquí se encontraría el primer punto de comparación entre arte y ciencia, el parangón que se produce en cada disciplina:

This paragon dispute is not unknown to the historian of science. Here we have the first parallelism between art and science. The human sciences or the social sciences are not the model science any longer since many decades. Since the age of the Industrial Revolution the natural sciences have taken over as a model science. But like the visual arts again the question remains who can demand priority - physics, mathematics, chemistry, biology. (Weibel, 1998, p. 167).

El segundo punto donde Weibel sitúa la comparación entre arte y ciencia es el método. El problema que encuentra es que mientras que la ciencia sí se ha conceptualizado en términos metodológicos, en las artes esta cuestión no es tan evidente. Sin embargo, el autor reivindica los esfuerzos realizados en el campo artístico en este sentido, situando sus orígenes en el Renacimiento y, posteriormente, en la fundación de la disciplina de la estética en el siglo XVIII. El panorama artístico presentaría, a diferencia de la supuesta unicidad del método científico, una pluralidad de métodos simultáneos. Sin embargo, Weibel apela a que en la ciencia también se produce una variabilidad del conocimiento científico, que es histórica, en la medida en que se han sucedido diversos paradigmas a lo largo de la historia de la ciencia. La pluralidad de métodos es, por tanto, un rasgo en común a ciencias y artes a pesar de que en la ciencia existe una cierta tendencia al reemplazo de un paradigma por otro y en las artes, en cambio, se percibe una mayor tolerancia por la coexistencia de métodos.

El planteamiento de Weibel es útil para contextualizar de una forma que consideramos adecuada el debate sobre la interdisciplinariedad en las relaciones arte y ciencia ya que apunta a la necesidad de precisar los términos que intervienen en la comparación, además de detectar una pluralidad de métodos tanto en artes como en ciencias que se integran, eso sí, de forma distinta en cada caso. El valor de su reflexión es que no pretende agotar la cuestión de la interdisciplinariedad certificando su existencia sino que deja la puerta abierta a la exploración del modo en que se establece la interdisciplinariedad entre manifestaciones concretas. Consideramos que esta idea es el punto de partida para el análisis de los mecanismos interdisciplinarios que caracterizan el bioarte ya que permite poner en valor una cuestión crucial: que el diálogo que se establece entre arte y ciencia en el contexto del bioarte pasa por la atención a la utilización artística de unos medios y unos espacios (los laboratorios) profundamente connotados en el ámbito de la investigación biológica. Creemos, 
por tanto, que es necesario plantear este diálogo entre arte y ciencia desde un punto de vista que trate de superar las limitaciones de la interdisciplinariedad concebida de arriba a abajo, es decir, evitando aplicar unas consideraciones teóricas que son necesariamente genéricas a la heterogeneidad de prácticas que conforman la realidad bioartística. En virtud de este enfoque teórico, el bioarte deberá ser analizado teniendo en cuenta su naturaleza material, así como las distintas modalidades de relación existentes entre arte y ciencia teniendo en cuenta la heterogeneidad de prácticas que acoge el término "bioarte".

A continuación se propone, como estudio de caso de la interdisciplinariedad, el análisis de las distintas modalidades de relación que el artista ha establecido con el laboratorio científico en el caso del bioarte con el fin de valorar las implicaciones que tienen los distintos usos artísticos que se han hecho de este entorno científico de investigación.

\section{El artista en el laboratorio: modalidades y disidencias}

Del mismo modo que el taller artístico ha sido durante siglos el espacio propio de los artistas, el laboratorio es el lugar por excelencia de las ciencias experimentales. El término "laboratorio" ha empezado a utilizarse en el ámbito artístico de un modo metafórico, como sinónimo de espacio de experimentación e innovación. Sin embargo en el caso del bioarte los artistas trabajan en una estrecha relación con el laboratorio tal y como éste se concibe en el ámbito científico, aunque con una finalidad distinta, artística y no científica. El laboratorio es un lugar especializado que cuenta con los medios y las condiciones necesarias para desarrollar la fase experimental de toda investigación científica. El uso del laboratorio como espacio de creación artística o como fuente de técnicas y materiales es clave ya que no solo afecta a los espacios de creación sino a la misma naturaleza material de la obra. La utilización artística de este espacio altamente especializado y connotado altera las relaciones disciplinares que se generan entre laboratorio y usuarios en el contexto de la investigación científica, abriendo la posibilidad a la interpretación de la biotecnología desde un punto de vista no científico. En este apartado nos proponemos revisar las distintas modalidades artísticas del laboratorio científico aludiendo a distintos casos en los que los artistas han hecho uso de este espacio.

Los primeros artistas que, desde principios de los años ochenta, incorporaron las técnicas de la biología contemporánea se encontraron con una dificultad de acceso al laboratorio y, por tanto, a las actividades que se pueden desarrollar en él, tal y como explican los artistas George Gessert (Gessert, 1999) y Amy Youngs (Youngs, 2000). Esta situación ha cambiado sensiblemente con el inicio del siglo XXI, en primer lugar, por la creación de laboratorios interdisciplinares, como el laboratorio SymbioticA de Perth (Australia); en segundo lugar, por la permeabilidad de algunos laboratorios científicos, que han permitido la realización de estancias de investigación a artistas, con el ejemplo pionero de Joe Davis, que ha trabajado en laboratorios del Massachusetts Institute of Technology (MIT) desde los años ochenta; y, en tercer lugar, por el surgimiento de iniciativas de amateurismo que han propuesto la extracción de las técnicas y procedimientos de la investigación biológica fuera de las paredes del laboratorio. 
La relación entre científicos y artistas cuando éstos comparten espacio de trabajo se ha conceptualizado en términos muy distintos que parten desde la "colaboración" (Menezes, 2002) entre científicos y artistas, hasta el "parasitismo" del artista con respecto al laboratorio (Critical Art Ensemble, 2002). En algunos casos, incluso, se ha planteado la participación del artista como una "traición", en la medida en que la orientación crítica de algunas investigaciones bioartísticas puede generar desconfianza entre los científicos que lo acogen (Prophet, 2011). En cualquier caso, la utilización de un espacio asociado a la investigación científica para fines no relacionados con la ciencia resulta en una experiencia tan controvertida como enriquecedora porque plantea preguntas que difícilmente surgen en el marco disciplinar en el que estos espacios cobran sentido.

Las experiencias de los artistas en laboratorios científicos son muy diversas, desempeñando un papel muy distinto en el proceso artístico en cada caso. Aunque no todos los bioartistas han explicado con el mismo detalle su relación con el laboratorio, es posible reconstruirla a través de algunos casos que consideramos representativos. En función del análisis de los distintos casos hemos identificado tres modalidades de relación entre el artista y el laboratorio en el marco del bioarte.

\subsection{El laboratorio como atelier}

La utilización del laboratorio como espacio de trabajo es una de las características genuinas y comunes a la gran mayoría de artistas que trabajan en el marco del bioarte. Sin embargo, recurrimos al término "atelier" por sus connotaciones en la Historia del Arte, que ayuda a enfatizar la idea de que el laboratorio científico deviene, en los casos que estudiaremos, en un espacio técnico pero sobre todo en un espacio que el artista hace suyo para concebir y desarrollar sus proyectos artísticos. No se trata, en el punto que nos ocupa, de artistas que conciben su taller como un laboratorio (en términos metafóricos) sino de la utilización (y, si cabe, apropiación) de un espacio genuinamente científico y de su resignificación en clave artística, con las problemáticas conceptuales que eso conlleva. El núcleo de estas problemáticas es, sin duda, de carácter disciplinar, en la medida en que se utiliza un espacio para unos fines (los artísticos) para los que no ha sido concebido.

La naturaleza controvertida de la relación entre arte y ciencia, que se podría conceptualizar en términos de choque disciplinar más que de cooperación -recordemos la acertada expresión con la que Jane Prophet se refiere a ello, como "una cooperación razonablemente traicionera" (Prophet, 2011)- constituye la piedra de toque de las aportaciones que un enfoque y uso artístico de la biotecnología puede aportar a la comprensión de la biotecnología. Al constituirse como usuario de un espacio científico, el bioartista reivindica para el arte una consideración simétrica a la del biólogo por lo que respecta a la legitimidad en el uso del laboratorio. La consideración simétrica de bioartistas y científicos en la utilización del laboratorio se encuentra, sin embargo, con una asimetría de carácter disciplinar, en la que la asociación entre biotecnología y ciencia se encuentra legitimada (o naturalizada) mientras que la asociación entre biotecnología y arte no lo está. Es precisamente en esta asimetría donde se encuentra, en nuestra opinión, el potencial crítico del bioarte. En otras palabras, el potencial crítico del bioarte reside en la capacidad de revelar 
el estado de asociación entre biotecnología y ciencia (que se encuentra, antes de la aparición en escena del bioarte, naturalizada) mediante la propuesta de una nueva alianza que la desnaturaliza, como es la asociación entre arte y biotecnología.

Aunque son diversos los artistas que se han servido del laboratorio científico como atelier, nos centraremos en tres casos en los que esta relación se puede documentar de una forma más precisa, tratándose además de artistas sumamente emblemáticos en el contexto del bioarte: Joe Davis, Marta de Menezes y el colectivo Tissue Culture \& Art (vinculado al laboratorio SymbioticA). En cada caso, además de reseñar las distintos modos en que establecieron un vínculo con el laboratorio artístico, escogeremos una obra artística que nos permita incorporar al análisis de estas condiciones de trabajo, algún resultado artístico.

El artista Joe Davis (1950), uno de los padres del bioarte, es pionero en la utilización del laboratorio científico con fines artísticos, deviniendo el primer artista que utiliza un laboratorio como espacio de producción artística. Davis ejerció como artista residente en el Massachusetts Institute of Technology (MIT) de Harvard, hasta que en 1992 el biofísico Alexander Rich le ofreció una plaza como investigador en el Departamento de Biología del mismo centro, donde prosiguió su investigación artística. Davis ha ejercido también la docencia en el MIT y en la Rhode Island School of Design. No cabe duda de que el trabajo pionero de Davis en la incorporación de las técnicas de $\mathrm{ADN}$ recombinante a la práctica artística (que ha resultado en obras como Microvenus -1986-, The Riddle of Life -1993- o Milky Way DNA -2002-) tiene tanto que ver con su interés en ese ámbito como en la posibilidad de conocer las investigaciones y utilizar las instalaciones especializadas de un centro puntero en investigación como lo es el MIT. Esto convierte a Davis en el único bioartista que durante la década de los ochenta y hasta bien entrados los años noventa ha trabajado de una forma regular en un laboratorio científico, con la posibilidad de utilizar las tecnologías asociadas a la biología molecular. Además, su estancia continuada en un mismo centro de investigación especializada lo hace único en el ámbito del bioarte, a diferencia de otros artistas que realizan estancias puntuales en centros de investigación científica.

Con el fin de valorar los resultados artísticos que Davis ha podido obtener de sus vínculos con el laboratorio, resulta pertienente aludir al proyecto Microvenus, la primera "molécula artística" del artista, realizada en 1986. Davis utilizó como modelo una imagen ancestral de la feminidad, equivalente a la superposición entre una "Y" y una "I" como base del proyecto. Reconstruyó esta imagen por medio de una composición rectangular compuesta de ceros y unos en donde los unos van componiendo la forma, del siguiente modo: 
Esto le permitió traducir la imagen a un código binario, compatible con una secuencia genética, formada por los cuatro nucleótidos, que pudo sintetizar en el laboratorio. El código de conversión utilizado por Davis fue el siguiente: en función del número de veces que se repetía un número (de una a cuatro veces) asignó un nucleótido, del siguiente modo: Citosina $=$ un número; Timina=dos números; Adenina $=$ tres números; Guanina $=$ cuatro números. Es decir que la secuencia de ceros y unos, que comenzaba "1-0-1-0-1-0-111-000-1-0000-..." se transformaría en "CCCCCCAACG...". La sintetización de la molécula de ADN se hizo con la ayuda de Martin Bottfielf en Harvard. Esta molécula sintética de ADN (que codificaba la imagen de la feminidad) fue introducida en una bacteria e.coli, muy utilizada en los laboratorios científicos para este tipo de procedimientos. En el análisis que hace de su obra, Davis pone de relieve el valor del elemento vivo, en este caso la bacteria que contiene la "molécula artística de ADN":

The Microvenus DNA now resides in a bacterium that is a delicate 'living carriage'that cannot ordinarily withstand exposure to air and sunlight. In fact, it was chosen because it could be easily destroyed. (Davis, 1996, p. 71).

La trayectoria artística de Marta de Menezes (1975) es también representativa de la utilización de laboratorios diseñados para la producción científica con fines artísticos aunque, a diferencia de Davis, Menezes no se ha establecido de forma permanente en un mismo laboratorio sino que, en función de cada proyecto artístico, ha recurrido a laboratorios especializados en las técnicas que le interesaba explorar. En su caso, el inicio de su trabajo en el laboratorio se remonta a 1999, en el contexto de la preparación de su obra Nature?, siendo éste el momento en el que se puede apreciar un interés creciente por parte de artistas en la experimentación con técnicas biológicas, como es el caso de Eduardo Kac o el colectivo Tissue Culture \& Art. Menezes ha realizado estancias en centros distintos en función de los intereses que guiaban sus proyectos, convirtiéndose probablemente en la artista que ha trabajado con una mayor variedad de técnicas y procedimientos del laboratorio. A propósito del mencionado proyecto Nature?, la artista realizó una estancia en el laboratorio del profesor Paul Brakefield (Universidad de Leiden, Holanda) donde se familiarizó con la disciplina de la biología del desarrollo y con las técnicas de microcauterización que ese grupo utilizaba para sus investigaciones. Es sintomático de esta colaboración el hecho de que Menezes, como la gran mayoría de artistas, cita a todo el equipo de investigación en los créditos de su obra en su página web (www.martademenezes. com). En proyectos posteriores, Menezes ha contado con la colaboración de otros laboratorios y equipos de investigación. Para la obra Nucleart (2000-2002) obtuvo la colaboración del laboratorio de la Dra. Ana Pombo, en el Imperial College of London. También realizó una estancia en el laboratorio SymbioticA (Australia) para desarrollar el proyecto Tree of Knowledge (2004-2005). Además ha contado con ayudas puntuales de científicos para el desarrollo de otros proyectos como Inner Cloud (2003) o Decon (2007). Marta de Menezes ha analizado su experiencia artística en el laboratorio en su texto, de título programático, "The laboratory as an art studio" (Catts, 2002), teorizándolo como un espacio de "colaboración" entre arte y ciencia mediante la que pueden generarse aportaciones recíprocas. Por otro lado, Menezes 
apunta al valor de laboratorio como fuente de técnicas, además de mencionar que es un entorno seguro para experimentar, una concepción que será radicalmente distinta a la de las propuestas en la línea del "Do It Yourslef" (DIY) o del amateurismo, que se abordarán más adelante.

Su obra Nature (1999-2000) es uno de los primeros ejemplos de bioarte en el que la relación entre arte y biología, entre práctica artística y laboratorio, no implica un trabajo a nivel genético. Marta de Menezes se centró en el área de investigación conocida como biología del desarrollo, que estudia el modo en que se produce el desarrollo que media entre una célula original y la complejidad que adquiere el organismo desarrollado. Para el proyecto Nature?, Menezes trabajó en el citado laboratorio dirigido por Paul Brakefield en la Universidad de Leiden (Holanda). Allí utilizó la técnica de la microcauterización sobre mariposas en estado de pupa, interfiriendo en el desarrollo de una de sus alas, sin heridas ni cicatrices. Una de las alas de cada mariposa incorpora un patrón que es fruto de la intervención en su desarrollo (y que por tanto está compuesto por células normales, no de pigmentos o añadidos). Menezes considera especialmente relevante que dicho patrón no solo es único sino que no ha sido generado por la naturaleza, en sintonía con la interpretación inaugurada por Steichen y continuada por George Gessert y también Eduardo Kac, que incide sobre la posibilidad de generar seres vivos al margen de la evolución natural. Pero a diferencia de los anteriores, las modificaciones que realiza Menezes en las mariposas no son genéticas, por lo que esta marca no se transmitirá a la progenie, haciendo a la mariposa única, ya que ese rasgo solo existirá hasta la muerte de la mariposa.

Además de estas estancias de artistas en laboratorios ajenos, una de las manifestaciones más interesantes del bioarte ha sido la de habilitar laboratorios científicos dedicados a la práctica artística, surgidos en parte como respuesta a las dificultades que han tenido los artistas para acceder a estos entornos especializados. El ejemplo pionero es el del laboratorio SymbioticA, en The University of Western Australia (Perth) que fue fundado en 2000, aunque sus orígenes se encuentran en la formación del colectivo Tissue Culture \& Art en 1996, formado por los artistas Oron Catts e Ionat Zurr, promotores de este laboratorio. SymbioticA persigue el trabajo conjunto de artistas e investigadores en relación con la práctica biológica. El laboratorio organiza residencias de artistas (de las que destacamos la de Marta de Menezes, que ya hemos mencionado, y la de Stelarc y Orlan, para la realización de las obras Extra ear 1/4 scale -2003- y Harlequin coat -2007-, respectivamente), además de talleres, exposiciones y simposios, tal y como se documenta en su sitio web (www.symbiotica.uwa.edu.au). El objetivo de este laboratorio artístico, en sintonía con el del colectivo artístico de Tissue Culture \& Art, es la promoción de una mayor comprensión y articulación de las ideas que rodean al conocimiento científico desde una posición crítica que aborde las implicaciones éticas y culturales por medio del trabajo directo en el laboratorio.

La primera obra que realizó este colectivo artístico se dio a conocer en el marco del Festival Ars Electronica 2000, bajo el título Tissue Culture \& Art(ificial) Wombs Semi Living Worry Dolls. En este proyecto los artistas utilizaron como modelo las pequeñas muñecas guatemaltecas a las que los niños cuentan sus preocupaciones $\mathrm{y}$, 
tras ponerlas debajo de la almohada, hacen que estos problemas desaparezcan. Los artistas reproducjeron varias de estas muñecas en material estéril, impregnándolas de células por lo que, al cabo de un tiempo, las muñecas quedaban recubiertas de tejido celular. Las muñecas inertes devienen así en elementos vivos, sensibles al ambiente en que se encuentran, hasta el punto que han de ser conservadas en un biorreactor que mantenga las condiciones de temperatura, humedad, esterilidad y nutrientes que requieren los tejidos para que no mueran. De un modo simbólico, los artistas asignaron un nombre a cada muñeca, nombres relacionados con miedos y esperanzas asociados a la biotecnología, y utilizando las primeras letras del abecedario: Verdades Absolutas (A: Absolute truths), Biotecnologías (B), Capitalismo (C), Demagogia y Destrucción (D), Eugenesia (E), Miedo (F: Fear), (No hay muñeca G porque, según los artistas, los "Genes" están en todas), Esperanza (muñeca H: Hope). En algunas de las versiones posteriores de este proyecto, como la de la exposición Synth-ethic que tuvo lugar en el Museo de Historia Natural de Viena (Hauser y Schmidt, 2011), el público asistente también puede susurrar sus miedos a las muñecas, a través de un micrófono, haciendo que las palabras se oigan dentro del biorreactor donde habitan las muñecas lo que afecta al desarrollo de las mismas y permite integrar, al menos en un plano simbólico, las palabras del público a su desarrollo.

El objetivo de Tissue Culture \& Art en este proyecto (y también en los siguientes) es reflexionar sobre la nueva ontología de la naturaleza en la era biotecnológica, a través del concepto de "semivivo" (semiliving) que ellos aplican a estas comunidades de tejidos, denominando a sus obras, genéricamente, semiliving sculptures. El concepto de "semivivo" remite a que estas entidades, que son fruto de la intervención del ser humano, son difícilmente clasificables en las categorías tradicionales (objetoser, animado-inanimado, vivo-muerto, artificial-natural), ubicándose en un limbo conceptual. Por otro lado, la urgencia de su proyecto tiene que ver con el argumento de que estas tecnologías y estos seres-objeto no son ficciones sino que ya existen en los laboratorios científicos: su proyecto consiste en la exploración de estas entidades semivivas, bajo la conciencia de que la tecnología está produciendo unos cambios en la naturaleza que se adelantan a su conceptualización. En sus propias palabras:

These sculptures are still in the realm of a symbolic gesture representing a new class of object/being. These objects are partly artificially constructed and partly grown/born. They consist of both synthetic materials and living biological matter from complex organisms. These entities (sculptures) blur the boundaries between what is born/manufactured, animate/inanimate and further challenge our perceptions and our relations toward our bodies and constructed environment. (Catts, Zurr, Ben-Ary, 2000).

\subsection{El laboratorio como fuente de técnicas y materiales}

El caso de Eduardo Kac (1962) es representativo de la segunda modalidad de relación entre el artista y el laboratorio, la de su utilización instrumental como fuente de materiales y técnicas. Algunas de sus producciones han contado con la colaboración de científicos y laboratorios, a pesar de que el artista no ha participado necesariamente en el desarrollo de todos los procedimientos de sus obras, sino que los ha obtenido por encargo. El artista ha de definir las características del proyecto, 
antes de su producción. Este modo de proceder recuerda al de algunos artistas contemporáneos, como Andy Warhol, quien delegaba, en muchas de sus obras, la fase de realización a sus ayudantes de la Factory, o Donald Judd, que transmitía las instrucciones para la producción de la obra a centros industriales que procedían a su fabricación. Aunque probablemente el precedente más remoto de este modo de actuar es el del artista László Moholy-Nagy quien, en sus Telefonbilder (realizados a partir de 1922), daba instrucciones telefónicas a la fábrica, que se encargaba de la realización material de la obra.

Es importante destacar que el hecho de que no sea el artista el que desarrolle las técnicas y procedimientos necesarios para la producción de la obra no implica que éste considere que su realización sea secundaria: al contrario, recordemos que para Eduardo Kac la existencia material de su obra es fundamental, en virtud de su afirmación "Bio art is in vivo". Kac otorga a su obra un alto valor demostrativo (sobre la misma posibilidad de ampliar la biodiversidad artificialmente, o sobre las controversias que provoca la integración de transgénicos en la sociedad), pero no necesariamente experimental, lo que lo acerca a esas aproximaciones conceptuales (de Moholy-Nagy a Judd, pasando por Warhol) en las que el artista concibe la obra y se interesa por su realización, pero sin necesidad de intervenir materialmente en su producción.

En los textos que Eduardo Kac ha dedicado a describir y analizar sus obras no siempre pone de manifiesto esta cuestión sino que en muchos casos se limita a describir la técnica, sin especificar si él ha sido el ejecutor de la misma o si esto se ha producido a través de un encargo: esto lo diferencia en parte de los artistas mencionados anteriormente. Uno de los ejemplos más emblemáticos de la ausencia del artista en el proceso de realización de la obra es el del conejo transgénico Alba, que constituye el núcleo del proyecto GFP Bunny (2000). Kristen Philipkoski ha publicado que no solo Eduardo Kac no participó en el desarrollo del conejo sino que ni siquiera fue realizado para él ya que era uno de tantos conejos con los que contaba el laboratorio visitado por Kac y su intervención se habría limitado a escogerlo. Philipkoski reproduce las afirmaciones del científico que ayudó a Kac en esta obra, Louis-Marie Houdebine, al respecto:

"When E. Kac visited us, we examined three or four GFP rabbits", Houdebine said. "He decided that one of them was his bunny, because it seemed a peaceful animal." Houdebine says he would not have agreed to engineer one animal specifically for any artist. (Philipkoski, 2002).

Nos encontraríamos, en este caso, ante una trasposición literal del concepto duchampiano de ready made (literalmente, "ya hecho") al arte biotecnológico, lo cual tiene implicaciones éticas adicionales, al tratarse de un material sensible como es un ser vivo. En otros proyectos como Natural History of the Enigma (2003-2007) el artista contó con la colaboración de científicos que le permitieron desarrollar determinadas fases del proyecto, tal y como él mismo recoge en el texto que dedica a esta obra: por ejemplo, Bonita L. Baskin le ayudó a aislar y clonar la inmunoglobulina de su muestra, y el profesor Neil Olszewski certificó que este gen solo se expresaba en las venas rojas de la petunia. 
Por último, creemos que es importante destacar una última faceta del artista con respecto al laboratorio. Se trata, precisamente, de la visibilización de la naturaleza críptica del laboratorio científico en el caso de su obra GFP Bunny, debido a los impedimentos que puso el responsable del laboratorio en relación con la liberación de la coneja, según Louis Houdebine:

"My director did not understand," Houdebine said. "He said I should not give the rabbit (to someone) outside the lab." (Philipkoski, 2002).

Además de las campañas que Kac protagonizó, reclamando la liberación del conejo (bajo el lema "Free Alba"), el artista ha reivindicado la necesidad de liberar al animal del laboratorio con el fin de favorecer una integración social de los organismos genéticamente modificados. Este hecho se tradujo en una controversia entre partidarios y detractores de la liberación del conejo, documentada exhaustivamente por el artista mediante una amplia selección de artículos, e-mails y posts, que recoge en su página web (www.ekac.org), y que considera parte del proyecto artístico. Todas estas cuestiones que rodean a la obra (reacciones públicas, reivindicaciones del artista, documentos y nuevas obras del artista) han acabado por constituir la obra en sí, en ausencia del conejo que nunca llegó a salir del laboratorio, dándose la paradoja de que la que probablemente es la obra más conocida del bioarte solo se conoce por la documentación que la sustituye. De hecho la fotografía que documenta la existencia de la coneja parece haber estado manipulada con photoshop para que cuente con el tipo de luminosidad verdosa que supuestamente la caracteriza (De Vicente, 2012) lo que arroja, si cabe, más dudas sobre su existencia.

\subsection{El amateurismo como rechazo del laboratorio}

La tercera modalidad de la relación entre bioarte y laboratorio es la que propone desvincular las técnicas de la investigación biológica de ese contexto especializado. Esta tendencia está representada de forma pionera por los artistas Natalie Jeremijenko (1966) y Heath Bunting (1966) quienes iniciaron en 1998 el proyecto on-line The Biotech Hobbyist que tendrá continuidad en otro proyecto posterior realizado junto con Eugene Thacker. Este proyecto consistió precisamente en la recopilación de distintos protocolos que pueden realizarse de forma sencilla en un ámbito doméstico: por ejemplo el Micropropagation Kit, que da instrucciones para la clonación de árboles, o Skin Kit, que permite realizar cultivo tisular en una cocina doméstica.

El colectivo Critical Art Ensemble (CAE) ha desempañado también una gran labor tanto en la teorización como en la puesta en práctica del amateurismo biotecnológico, cuestionando el valor ideológico del laboratorio científico. En su libro The Molecular Invasion (Critical Art Ensemble, 2002) CAE propone la apropiación y subversión de los productos y procesos de la biotecnología, entendida como un sistema de poder, proponiendo una forma de activismo artístico o artivismo. Los objetivos de este artivismo biotecnológico son fundamentalmente tres: la "demistificación" ("demystification", en el idioma original) de las biotecnologías; la promoción de un pensamiento crítico, y el acceso público al conocimiento y las tecnologías biológicas. Uno de los proyectos más representativos a este respecto es Free Range Grain (2003- 
2004), en colaboración con Beatriz da Costa y Shyh-shiun Shyu, consistente en la articulación de un laboratorio portátil e itinerante que permitía a los asistentes testear alimentos transgénicos. Sin embargo, el hecho que mejor ilustra la necesidad de iniciativas como la que proponen Critical Art Ensemble, no es de índole artística: se trata del caso Kurtz, que se traduce en la asociación entre bioarte y bioterrorismo, cuyo origen se encuentra en la posesión de materiales biológicos inocuos fuera del laboratorio científico, en la casa de Steve Kurtz, uno de los mimebros fundadores de CAE (Mitchell, 2010, pp. 49-51).

El tipo de artista que se sitúa en esta tercera modalidad está íntimamente relacionado con el artista activista. Será precisamente Beatriz Da Costa -colaboradora ocasional de Critical Art Ensemble- la que, en un texto de 2008, teorice sobre la figura de lo que ella denomina "political technological artist", en su texto "Reaching the Limit. When Art Becomes Science" (Da Costa, 2008). En él, Da Costa describe las características del artista activista, así como sus fuentes teóricas, su perfil y las dificultades que va a encontrar en el ámbito de las biotecnologías. Las habilidades que, para Da Costa, deben caracterizar a este artista son las siguientes: la vocación contestataria y contextual, la concepción metacrítica de los espacios (laboratorios) y los medios (técnicas, tecnologías, habilidades) utilizados por los bioartistas y la reivindicación de un amateurismo científico. Es interesante destacar que Da Costa, en su voluntad de cruce de las fronteras disciplinares, confiere poca importancia a la consideración artística de las intervenciones del artista activista ya que su valor se encuentra más en su posibilidad de intervenir en los contextos sociopolíticos que en su mera interpretación artística, una característica que comparte con la mayoría de artistas implicados en el activismo.

\section{Conclusiones}

El problema inicial al que nos hemos enfrentado es la existencia de un modelo analítico generalista que interpreta la interdisciplinariedad en términos abstractos, que resulta ineficaz para comprender el modo particular en que el bioarte puede interpelar o verse interpelado por la biología desde un punto de vista disciplinar. Por ello hemos propuesto un modelo de análisis inverso, que conciba el diálogo entre arte y ciencia de abajo a arriba, es decir, partiendo de las particulares relaciones que se manifiestan entre arte y biología en el contexto de las prácticas bioartísticas. De este modo hemos podido analizar algunas de las implicaciones interdisciplinares del bioarte, entendiéndolo como un agente transformador del contexto tecnocientífico en el que se ubica, en virtud de la utilización artística de los medios de la biología contemporánea en el contexto del laboratorio, estableciendo tres modalidades de relación.

Si bien el análisis de cada caso artístico permite identificar particularidades en la relación entre el artista y el laboratorio científico, sí que puede establecerse una valoración de carácter general, que agrupa el conjunto de experiencias artísticas en el laboratorio científico o, en otras palabras, en la resignificación en clave artística de un entorno científico sumamente especializado. El trabajo en el laboratorio implica un ejercicio de descontextualización de la naturaleza, que no es ajeno a otras manifestaciones del arte del siglo XX y, muy especialmente, de los proyectos del arte 
de la tierra de Robert Smithson. Las comparaciones de manifestaciones artísticas que, como el bioarte, se han gestado al calor del llamado "arte de los nuevos medios" son muy excepcionalmente comparadas con otras manifestaciones del arte contemporáneo que podríamos denominar "mainstream". En nuestra opinión, estas comparaciones permiten dimensionar el valor de las manifestaciones artísticas, relativizando el valor de lo tecnológico (no renunciando a él), y previniendo análisis cercanos al determinismo tecnológico. En el caso que nos ocupa, la comparación del bioarte con Smithson resulta especialmente pertinente por lo que respecta a la reflexión sobre las nociones de contexto y descontextualización que afectan al trabajo artístico en el laboratorio, que hemos analizado en este artículo.

Desde un punto de vista conceptual, obras como Spiral Jetty (definida como site por Smithson) se relacionan con lo que el artista denomina non-site, que designa el desplazamiento de materiales procedentes de un territorio al contexto de la galería, en un gesto descontextualizador, análogo al que se deriva de la técnica del ready made. Lo interesante de esta contraposición es la conciencia de lugar que muestra Smithson en el trabajo con la naturaleza: el site plantea una sintonía entre el lugar y la obra exterior, mientras que el non-site establece una relación entre el lugar y la obra interior. La descontextualización a la que el non-site somete a los materiales se enfatiza por el hecho de que este tipo de obras suelen acompañarse de documentación gráfica que remite al lugar de donde ha sido extraído el material. En este caso, la naturaleza entendida como espacio y la naturaleza entendida como material no se corresponden, ofreciendo una imagen artificializada de la naturaleza por la vía de la deslocalización y el desplazamiento.

El concepto de non-site plantea una descontextualización material de la naturaleza que es equiparable a la utilización que se hace del laboratorio (espacio de trabajo para muchos bioartistas), entendiéndolo como un dispositivo de descontextualización de la naturaleza. Este paralelismo fue, de hecho, establecido por el mismo Robert Smithson, en una entrevista con Dennis Wheeler, donde el artista contrapone la existencia de una naturaleza aislada y controlada (con la que el científico trabaja en el contexto del laboratorio) a una naturaleza liberada y azarosa (a la que se enfrenta el científico que hace trabajo de campo):

The studio and the lab become places where you can control your information. But at the same time, the information you're controlling is not that interesting. It tends to be rather unnecessary. The stability of that is constantly challenged by the instability of these extraforces, like the storm over the island... (Simthson, Wheeler, 1996, p. 228).

\section{Referencias}

Catts, O. (ed.) (2002). The Aesthetics of Care? Nedlands: SymbioticA. School of Anatomy and Human Biology, University of Western Australia.

Catts, O; Zurr, I.; Ben-Ary, G. (2000). Tissue Culture and Art(ificial) Wombs. En: Stocker, G. y Schöpf, C. (eds.) Ars electronica 2000. Next Sex. Wien y New York: Springer.

Critical Art Ensemble (2002). The Molecular Invasion. Brooklin: Autonomedia. 
Da Costa, B. (2008). Reaching the Limit. When Art Becomes Science. En: Da Costa, B. y Philip, K. (eds.) Tactical Biopolitics. Art, Activism, and Technoscience. Massachusetts: MIT.

Davis, J. (1996). Microvenus. En: Art Journal, vol. 55, nº1, pp. 70-74.

De Menezes, M. (2002). The Laboratory as an Art Studio. En: Catts, O. (ed.) The Aesthetics of Care? Nedlands: SymbioticA. School of Anatomy and Human Biology, University of Western Australia, pp. 53-58.

De Vicente, J. L. (2002). Eduardo Kac, el arte de la quimera. En: El Cultural, $03 / 02 / 2012$.

Gessert, G. (1999). A History of Art Involving DNA. En: Stocker, G. y Schöpf, C. (eds.) Ars Electronica 99. LifeScience. Wien y New York: Springer.

Guillemin, R. (2010). Similarities and contrasts in the Creative Processes of the Sciences and the Arts. En: Leonardo, vol. 43, nº 1, 2010, pp. 59-62.

Hauser, J. (2005). Bio Art-Taxonomy of an Etymological Monster. En Schöpf, C. y Stocker, G. (eds.) Ars Electronica 2005 Hybrid - living in paradox. Wien: Ars Electronica.

Hauser, J y Schmidt, M. (comis.) (2011). Synth-ethic. Wien: BiofactionNaturhistorisches museum Wien, 14 de mayo-26 de junio.

Jeremijenko, N.; Thacker, E. (2005). Creative Biotechnology: A User's Manual. Newcastle: Locus+ Publishing Ltd.

Kuhn, T. S. (1969). Comments on the Relation of Art and Science, Comparative Studies in Society and History, 11, 1969. En: Kuhn, T. S. (1977). The Essential Tension. Selected Studies in Scientific Tradition and Change. Chicago-London: The University of Chicago Press, pp. 340-351.

López del Rincón, D.; Cirlot, L. (2013). Historiando el bioarte o los retos metodológicos de la Historia del Arte (de los medios). En: Artnodes. N. ${ }^{\circ} 13$, pp. 6271.. $<$ http://journals.uoc.edu/ojs/index.php/artnodes/article/view/n13-lopez-delrincon-cirlot/n13-lopez-del-rincon-cirlot-es $>\quad$ http://dx.doi.org/10.7238/a.v0i13 [Fecha de consulta: 08/01/2015]

Mandelbrojt, J. (2006). Similarities and Contrasts in Artistic and Scientific CreationDiscovery. En: Leonardo, vol. 39, n 5, pp. 420-425.

Mitchell, R. (2010). Bioart and the vitality of media. Seattle: Washington University Press.

Philipkoski, P. (2002). RIP: Alba The glowing bunny. En: Wired, 8 de diciembre 2002. En línea: <http://www.wired.com/medtech/health/news/2002/08/54399?cu rrentPage $=$ all $>$ [consulta 29/05/2013].

Prophet, J. (2011). El artista en el laboratorio: una cooperación razonablemente traicionera. En: Artnodes, 11, pp. 39-42. En línea: <http://journals.uoc.edu/ojs/ index.php/artnodes/article/view/artnodes-n11-prophet/artnodes-n11-prophetesp> [Consulta 03/11/2014]

Smithson, R; Wheeler, D. (1996) Four conversations between Dennis Wheeler and Robert Smithson. En: Flam, J. (ed.) Robert Smithson. The Collected Writtings. Berkeley y Los Angeles: University of California Press.

Snow, C. P. (1959) The two cultures and the Scientific Revolution. Cambridge: Cambridge University Press. 
Snow, C. P. (1963). The Two Cultures: and A Second Look. Cambridge: Cambridge University Press.

Vesna, V. (2000). Towards a Third Culture. Being in Between. En: Ascott, R.(ed.). Art, Technology, Consciousness. Mind@large. Bristol: Intellect.

Weibel, P. (1998). The Unreasonable Effectiveness of the Methodological Convergence of Art and Science. En: Sommerer, C. y Mignonneau, L. (eds.). Art@Science. Wien y New York: Springer, pp. 167- 180.

Youngs, A. M. (2000). The fine Art of Creating Life. En: Leonardo, vol. 33, nº 5, pp. 377-380. 